\title{
Tai Ji: The law of inflammatory response
}

\author{
Song Wan, MD, PhD \\ Anthony P. C. Yim, MD \\ See related article on page \\ 1122.
}

From the Division of Cardiothoracic Surgery, Department of Surgery, The Chinese University of Hong Kong, and the Prince of Wales Hospital, Hong Kong, People's Republic of China.

Received for publication March 26, 2002; accepted for publication April 25, 2002.

Address for reprints: Song Wan, MD, PhD, Division of Cardiothoracic Surgery, Department of Surgery, Prince of Wales Hospital, The Chinese University of Hong Kong, Shatin, Hong Kong, People's Republic of China (E-mail: swan@cuhk.edu.hk).

J Thorac Cardiovasc Surg 2002;124:1071-3

Copyright $(\odot 2002$ by The American Association for Thoracic Surgery

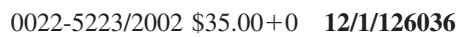

doi: $10.1067 / \mathrm{mtc} .2002 .126036$
Both are one in origin

and different only in name.

In its unity it is called the secret.

The secret's still deeper secret

is the gateway through which all miracles emerge.

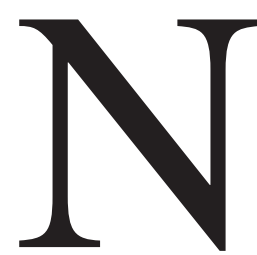

o other work of Chinese literature has attracted as much attention as Lao Zi's Dao De Jing, which has been translated more often than any other book except the Bible. The term Tai Ji (the primal beginning), possibly first defined by $\mathrm{Lao} \mathrm{Zi}$ at the end of the seventh century BC, played a major role in ancient Chinese philosophical thinking. The symbol of Tai Ji is the "Yin-Yang fish," so named because of the matching fish-shaped design (Figure 1), in which the white half of the circle containing a black dot stands for the "positive, masculine, warm" principle (Yang), and the complementary black half of the circle symbolizes the "negative, feminine, cold" principle (Yin). This figure has been used in endless representations of the coexisting positive and negative forces being within each other. As rationalized by Lao $\mathrm{Zi}$, the 2 complementary principles of Yin and Yang are the driving forces for the formation and evolution of all things in nature. This is probably what was meant by the "great secret of the unity of existence and non-existence."

Lao Zi's theory might still have countless interpretations 3000 years later. Interestingly enough, it also fits well with our current understanding of the inflammatory response after cardiac operations.

In this issue of the Journal, Kubala and colleagues ${ }^{1}$ compared the cytokine responses and neutrophil oxidative stress in patients undergoing heart transplantation versus other standard cardiac surgical procedures on cardiopulmonary bypass. At first glance, one might wonder whether they were comparing apples with oranges. There are several important differences between the 2 study groups of patients. For instance, the duration of cardiac ischemia in the transplant group was much longer, and the transplant recipients received immunosuppressive therapy, just to name 2 of these differences. Nonetheless, we agree with Kubala and colleagues that to explore the relationship between myocardial ischemia and reperfusion and the inflammatory response, transplant operations provide a unique model in the clinical setting.

There are some subtle but significant differences in the protocol of the current study compared with the one carried out in Brussels a few years ago, ${ }^{2}$ and these must be borne in mind when we examine the results. In particular, the numerous intergroup variables made it difficult to interpret the postoperative day 7 data in the current study. No samples were collected beyond 24 hours after aortic declamping in the Brussels study to minimize the unavoidable influence of immunosuppressive therapy. ${ }^{2}$ As far as the cytokine response is concerned, Kubala and colleagues ${ }^{1}$ nicely confirmed the previous findings, $, 2,3$ although in the current study the levels of interleukin (IL) 6 and IL-8 shortly after reperfusion appeared to be lower, whereas IL-10 levels were greater, than those in the Brussels study. ${ }^{2}$ It should be noted that 


\section{太极 \\ Tai Ji}

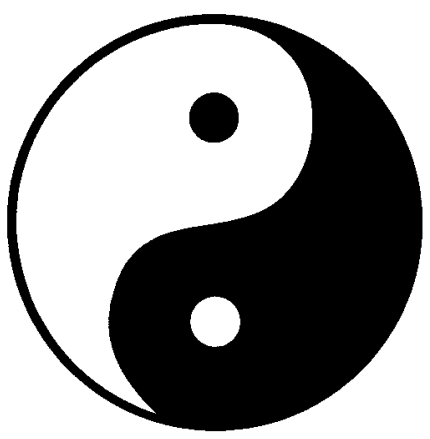

Figure 1. The pattern of Tai Ji.

Kubala and colleagues ${ }^{1}$ administered the first dose of methylprednisolone before the transplant procedure, whereas the transplant recipients in Brussels received their first dose of methylprednisolone 90 minutes after aortic declamping. ${ }^{2}$ We have previously demonstrated that the timing of steroid administration could alter the release of cytokines remarkably, ${ }^{3}$ which might explain the observed discrepancies.

Apart from the positive correlation between IL-6 and IL-8 in all patients, probably a more important finding in the study by Kubala and colleagues ${ }^{1}$ is the specific influence of immunosuppressive therapy on lipid peroxidation and phagocyte activity after the transplant procedure. Unfortunately, they did not provide data comparing the extent of myocardial injury (eg, postoperative release of cardiac troponin I). The question thus remains whether pharmacologic intervention, such as steroid pretreatment, is beneficial to patients undergoing cardiac operations ${ }^{3}$ or whether blocking IL-6 or IL- 8 could lead to improved myocardial preservation, as proposed previously. ${ }^{4,5}$

In search for answers, we might learn something from yet another kind of apples-versus-oranges comparison, namely the studies on coronary artery bypass grafting (CABG) with or without cardiopulmonary bypass. It is now widely accepted that, compared with conventional CABG, off-pump CABG is associated with a reduced inflammatory response, which might result in a significantly lesser degree of postoperative myocardial injury. ${ }^{6-8}$ However, IL-6 production after these 2 approaches has been repeatedly determined to be similar. ${ }^{6,9-11}$ In contrast, IL-8 production during and after conventional CABG was significantly greater than that after the off-pump procedure, ${ }^{6,10,12}$ and IL-8 level has been strongly correlated with postoperative release of cardiac troponin I. ${ }^{6}$ Meanwhile, the release of an anti-inflammatory cytokine, IL-10, is almost proportional to the levels of IL-8 during either on-pump ${ }^{13}$ or off-pump CABG. ${ }^{6}$
We are beginning to appreciate that a low-grade inflammatory response within the physiologic range is actually protective to the body. Some cytokines, such as IL-6, might even carry both proinflammatory and anti-inflammatory properties. ${ }^{13}$ Indeed, one might get overwhelmed by the high complexity of the body responses to injury. The more we know about inflammatory responses, the more complex they seem to become, and the further we appear to be from the true understanding of the process. Nevertheless, for myocardial injury after cardiac operations, accumulating evidence now indicates the following: (1) IL-6 and IL-8 might not exert equally important effects, and (2) instead of blocking each individual mediator, maintaining a balance between proinflammatory and anti-inflammatory responses might be more crucial.

One could imagine the concept of Tai Ji in the body's inflammatory response to injury. Nature has created in us a highly sophisticated system with various intrinsic counteracting forces to restore homeostasis once the system is disturbed. Pathology often represents an exaggeration of the physiologic response in an attempt to re-establish such balance. To focus all our attention on Yin and ignore Yang, or vice versa, might well turn out not to be the ideal approach one should take.

\section{References}

1. Kubala L, Čiž M, Vondráček J, Černý J, Němec P, Studeník P, et al. Perioperative and postoperative course of cytokines and the metabolic activity of neutrophils in human cardiac operations and heart transplantation. J Thorac Cardiovasc Surg. 2002;124:1122-9.

2. Wan S, Marchant A, DeSmet JM, Antoine M, Zhang H, Vachiery JL, et al. Human cytokine responses to cardiac transplantation and coronary artery bypass grafting. J Thorac Cardiovasc Surg. 1996;111:46977.

3. Wan S, DeSmet JM, Antoine M, Goldman M, Vincent JL, LeClerc JL. Steroid administration in heart and heart-lung transplantation: is the timing adequate? Ann Thorac Surg. 1996;61:674-8.

4. Sawa Y, Ichikawa H, Kagisaki K, Ohata T, Matsuda H. Interleukin-6 derived from hypoxic myocytes promotes neutrophil-mediated reperfusion injury in myocardium. J Thorac Cardiovasc Surg. 1998;116: 511-7.

5. Boyle EM Jr, Kovacich JC, Hèbert CA, Canty TG, Chi E, Morgan EN, et al. Inhibition of interleukin-8 blocks myocardial ischemia-reperfusion injury. J Thorac Cardiovasc Surg. 1998;116:114-21.

6. Wan S, Izzat MB, Lee TW, Wan IYP, Tang NLS, Yim APC. Avoiding cardiopulmonary bypass in multivessel-CABG reduces cytokine response and myocardial injury. Ann Thorac Surg. 1999;68:52-7.

7. van Dijk D, Nierich AP, Jansen EWL, Nathoe HM, Suyker WJL, Diephuis JC, et al. Early outcome after off-pump versus on-pump coronary bypass surgery: results from a randomized study. Circulation. 2001;104:1761-6.

8. Angelini GD, Taylor FC, Reeves BC, Ascione R. Early and midterm outcome after off-pump and on-pump surgery in Beating Heart Against Cardioplegic Arrest Studies (BHACAS 1 and 2): a pooled analysis of two randomised controlled trials. Lancet. 2002;359:1194-9.

9. Fransen E, Maessen J, Dentener M, Senden N, Geskes G, Buurman W. Systemic inflammation present in patients undergoing CABG without extracorporeal circulation. Chest. 1998;113:1290-5.

10. Czerny M, Baumer H, Kilo J, Lassnigg A, Hamwi A, Vukovich T, et al. Inflammatory response and myocardial injury following coronary 
artery bypass grafting with or without cardiopulmonary bypass. Eur J Cardiothorac Surg. 2000;17:737-42.

11. Struber M, Cremer JT, Gohrbandt B, Hagl C, Jankowski M, Völker B, et al. Human cytokine responses to coronary artery bypass grafting with and without cardiopulmonary bypass. Ann Thorac Surg. 1999; 68:1330-5.
12. Ascione R, Lloyd CT, Underwood MJ, Lotto AA, Pitsis AA, Angelini GD. Inflammatory response after coronary revascularization with or without cardiopulmonary bypass. Ann Thorac Surg. 2000;69:1198-204.

13. Wan S, Yim APC. Cytokines in myocardial injury: impact on cardiac surgical approach. Eur J Cardiothorac Surg. 1999;16(Suppl 1):S107-11.

\section{ON THE MOVE?}

Don't miss a single issue of the journal! To ensure prompt service when you change your address, please photocopy and complete the form below.

Please send your change of address notification at least six weeks before your move to ensure continued service. We regret we cannot guarantee replacement of issues missed due to late notification.

\section{JOURNAL TITLE:}

Fill in the title of the journal here.

\section{OLD ADDRESS:}

Affix the address label from a recent issue of the journal here.

\section{NEW ADDRESS:}

Clearly print your new address here.

Name

Address

City/State/ZIP

\section{COPY AND MAIL THIS FORM TO:}

Mosby

Subscription Customer Service

6277 Sea Harbor Dr

Orlando, FL 32887
OR FAX TO:

407-363-9661

N/M Mosby
OR PHONE:

800-654-2452

Outside the U.S., call

407-345-4000 